\title{
Silicon heterojunction solar cell characterization and optimization using in situ and ex situ spectroscopic ellipsometry
}

\section{Dean Levi, Eugene Iwaniczko, Matthew Page, Howard Branz, and Tihu Wang NREL, Golden CO USA}

2006 IEEE 4th World Conference on Photovoltaic Energy Conversion May 7-12, 2006 Hilton Waikoloa Village, Waikoloa, Hawaii 


\section{Disclaimer and Government License}

This work has been authored by Midwest Research Institute (MRI) under Contract No. DE-AC36-99G010337 with the U.S. Department of Energy (the "DOE"). The United States Government (the "Government") retains and the publisher, by accepting the work for publication, acknowledges that the Government retains a non-exclusive, paid-up, irrevocable, worldwide license to publish or reproduce the published form of this work, or allow others to do so, for Government purposes.

Neither MRI, the DOE, the Government, nor any other agency thereof, nor any of their employees, makes any warranty, express or implied, or assumes any liability or responsibility for the accuracy, completeness, or usefulness of any information, apparatus, product, or process disclosed, or represents that its use would not infringe any privately owned rights. Reference herein to any specific commercial product, process, or service by trade name, trademark, manufacturer, or otherwise does not constitute or imply its endorsement, recommendation, or favoring by the Government or any agency thereof. The views and opinions of the authors and/or presenters expressed herein do not necessarily state or reflect those of MRI, the DOE, the Government, or any agency thereof. 


\section{SHJ Solar Cell Fabrication}

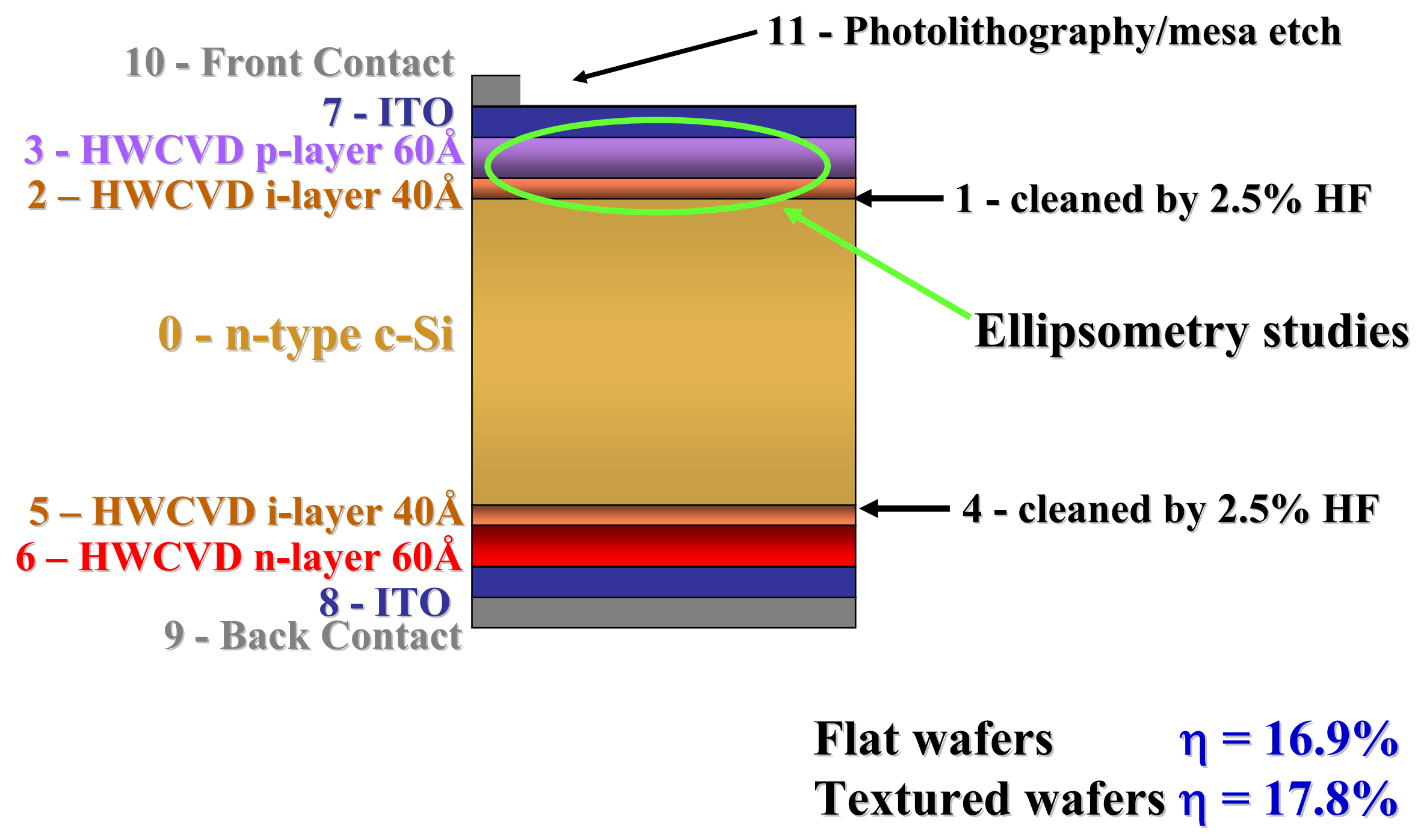




\section{HWCVD deposition system:}

\section{$i, n$, and $\mathbf{p}$ layers are deposited in separate chambers}

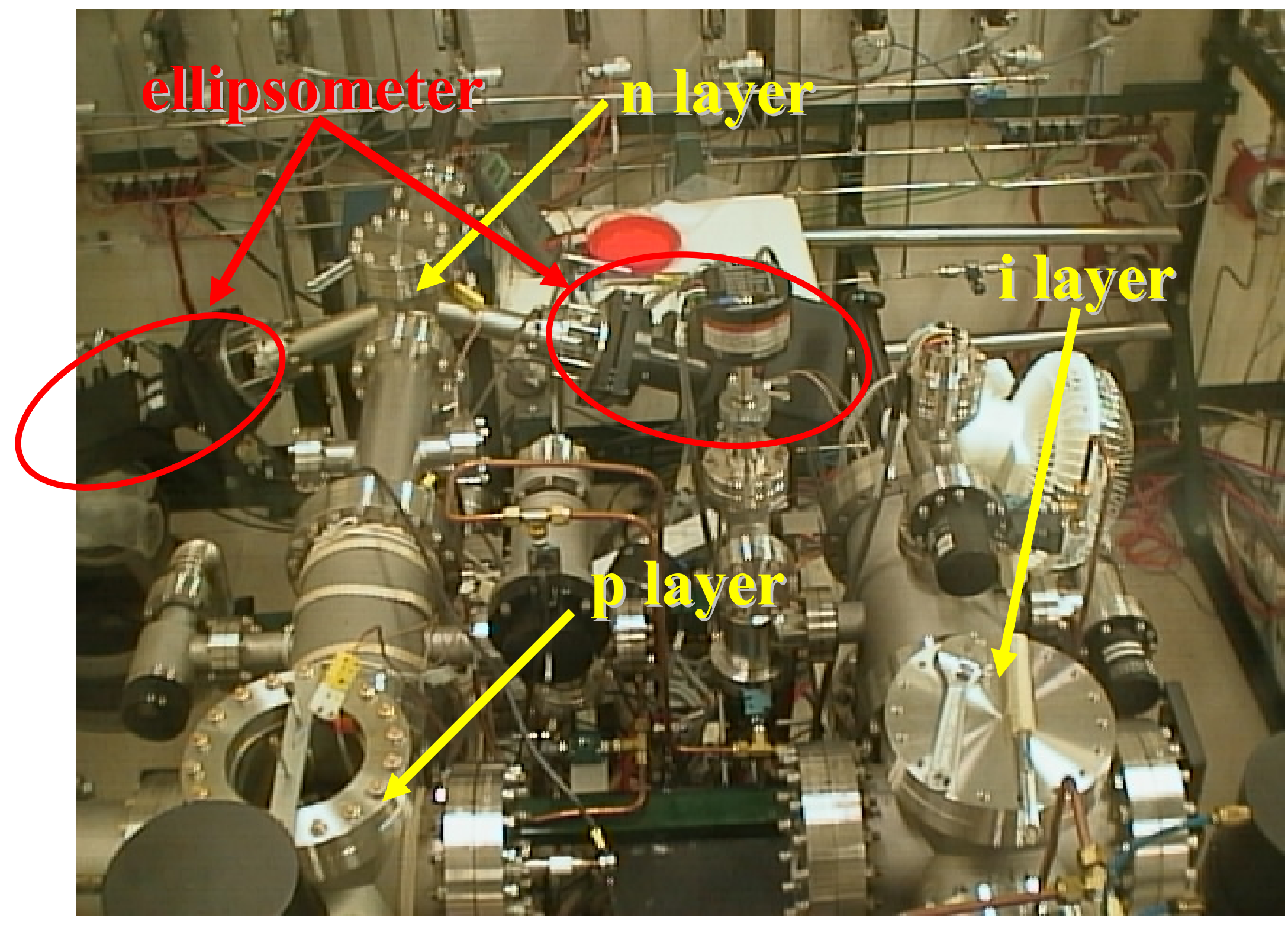




\section{Fabrication and characterization sequence}

- in situ RTSE

- Measures individual layers during deposition

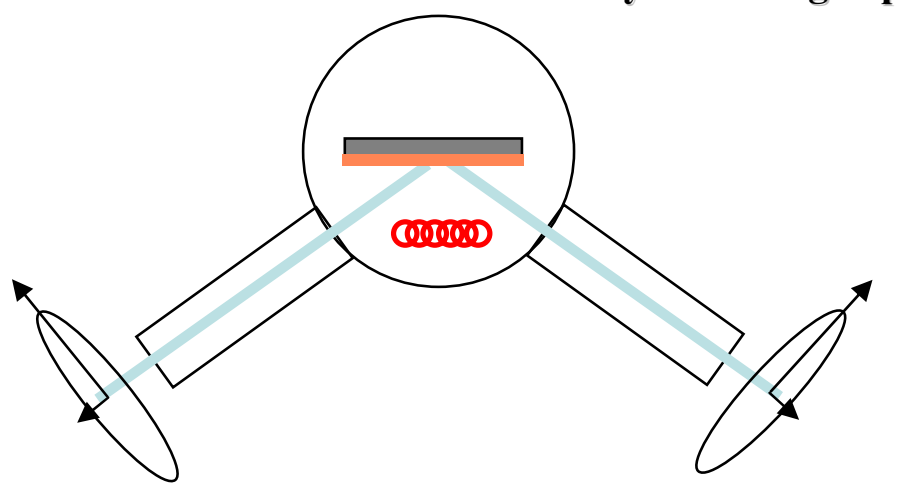

- layer thickness

- growth rate

- surface roughness

- optical properties

- crystallinity

- ex situ VASE

- Measures all layers at once in completed device

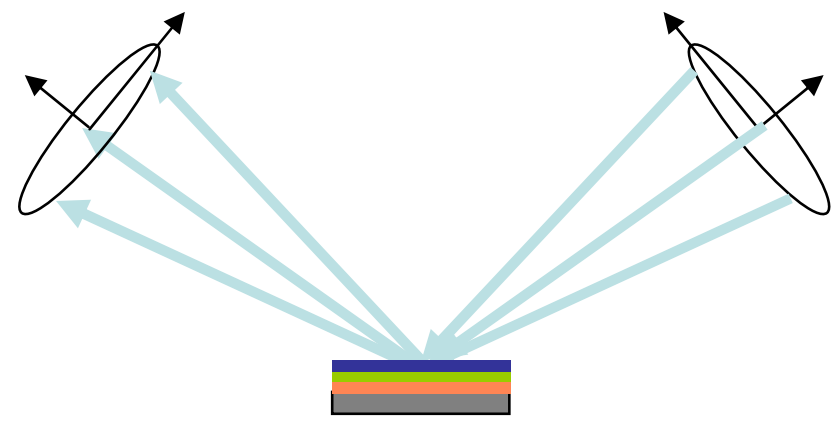

VASE

On actual devices

- layer thickness

- optical properties

- integrated optical response

- enables optical device modeling
c-Si wafer

1 etch

i-layer - front

vacuum

p-layer - front

etch

i-layer - back air break

n-layer - back air break

ITO deposition $2 \mathrm{x}$

Metalization 2x

Mesa etching \& isolation

PV device testing 


\section{in situ ellipsometry of a-Si:H growth}

- Surface roughness indicates growth dynamics

- Optical properties reveal structural and electronic properties 


\section{Evolution of surface roughness: $\mathbf{R}_{\mathrm{s}}$}

- The evolution of $R_{s}$ with bulk film thickness $d_{b}$ provides insight into the film growth process.

- $R_{s}$ can be represented as a function of $d_{b}$

Growth exponent $\beta$

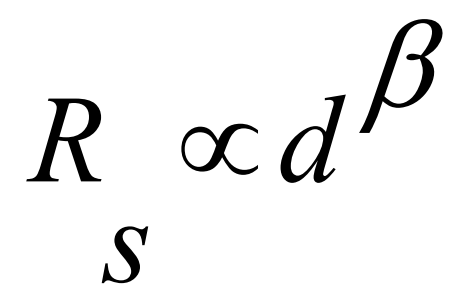

Universality classes

$\beta=0.5$ random deposition

$\beta=0.25 \mathrm{RD} w /$ diffusion

$\beta=0$ RD w/relaxation

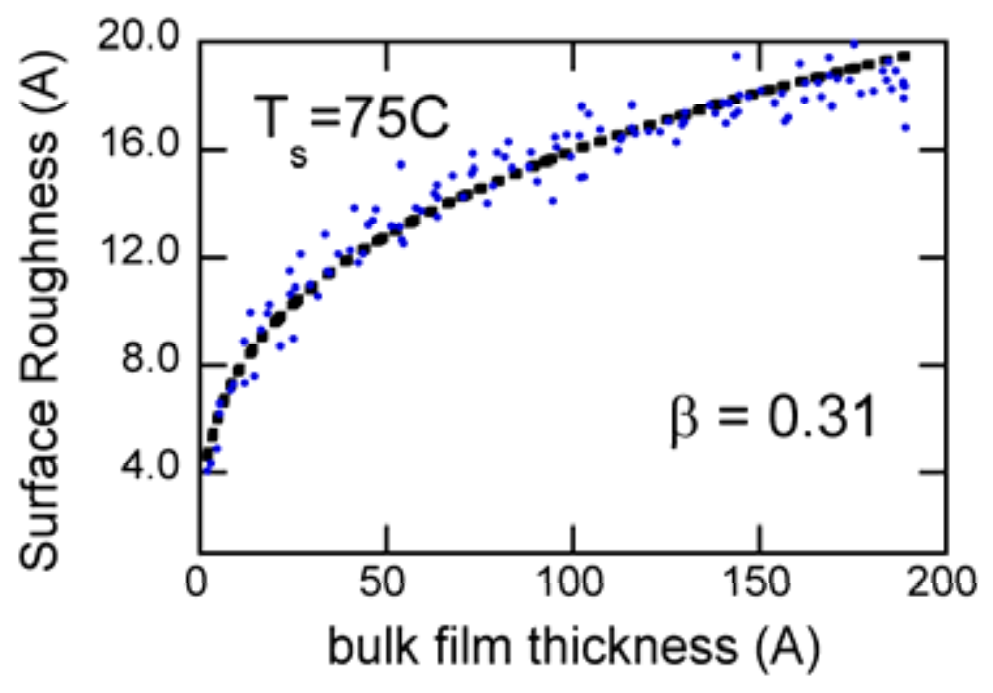




\section{Growth exponent for i-layer growth}

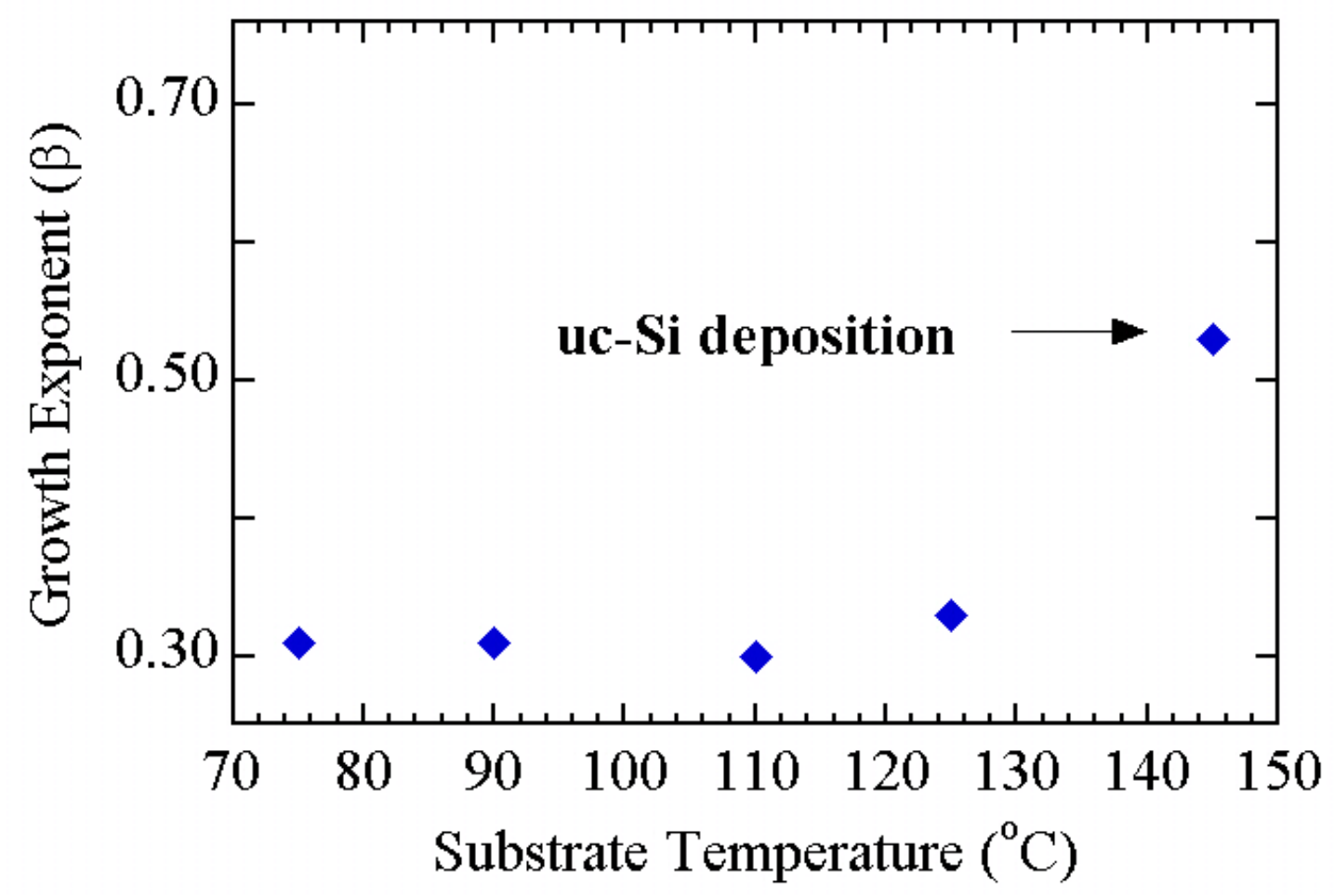

- $\quad \beta$ is nearly constant for $T_{s}<145^{\circ} \mathrm{C}$

- Abrupt increase in $\beta$ above $145^{\circ} \mathrm{C}$ indicates change in growth mode - uc-Si deposition 


\section{Optical properties vs $T_{s}$}

- i layers are deposited on oxide-free $<100>\mathrm{c}-\mathrm{Si}$ etched in $\mathbf{5 \%} \mathrm{HF}$
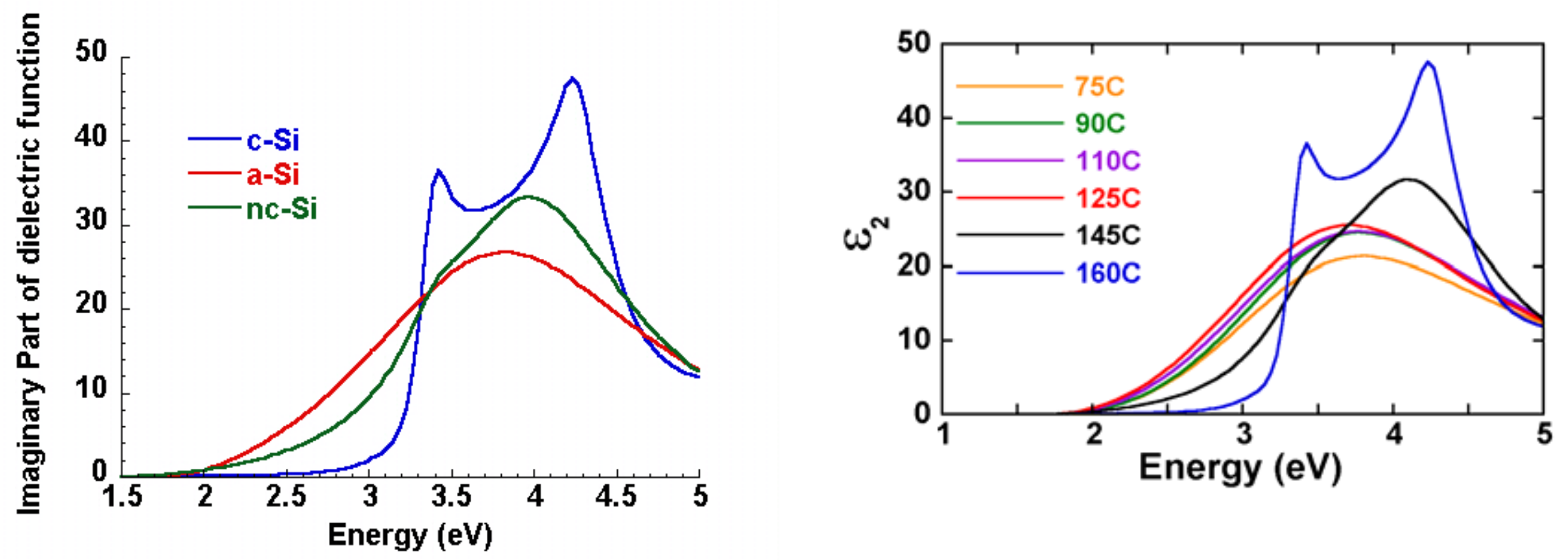

- 73C - 126C layers all a-Si:H

- 144C layer is mixed a-Si:H uc-Si:H

- 162C layer is epitaxial c-Si 


\section{Analysis of i-layer $\varepsilon_{2} T_{s}$ dependence}

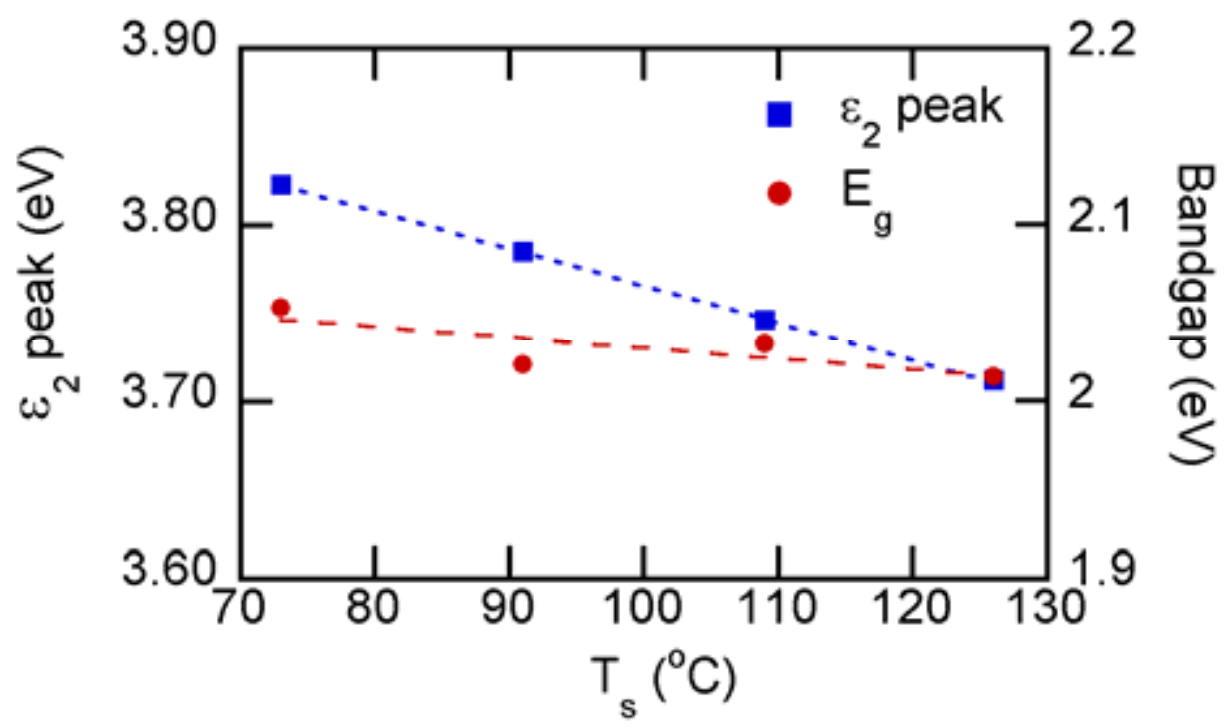

$$
\begin{aligned}
& \mathrm{d} \varepsilon_{2} / \mathrm{dT}_{\mathrm{s}}=-210 \mathrm{mev} / 100^{\circ} \mathrm{C} \\
& \mathrm{dE} E_{\mathrm{g}} / \mathrm{dT}_{\mathrm{s}}=-60 \mathrm{meV} / 100^{\circ} \mathrm{C}
\end{aligned}
$$

$$
\Delta\left(\mathrm{d}_{2} / \mathrm{dT}_{\mathrm{s}}\right)=17 \mathrm{meV} / 1 \text { at. } \% \mathrm{C}(\mathrm{H}){ }^{*}
$$

$12 \%$ drop in $\mathrm{C}(\mathrm{H}) \mathrm{w} / 100^{\circ} \mathrm{C}$ increase in $\mathrm{T}_{\mathrm{s}}$

* G.F. Feng, et al., Phys. Rev. B 45, 9103 (1992) 


\section{ex situ ellipsometry of finished devices}

- Ellipsometry measurement and analysis

- optical model to calculate R,T,A for each layer

- Compare calculations with device performance

- SHJ compared w/diffused junction

- 2 SHJ devices w/different p-doping 


\section{ex situ SE on finished devices}

\section{Example: single-sided n-i-p SHJ}

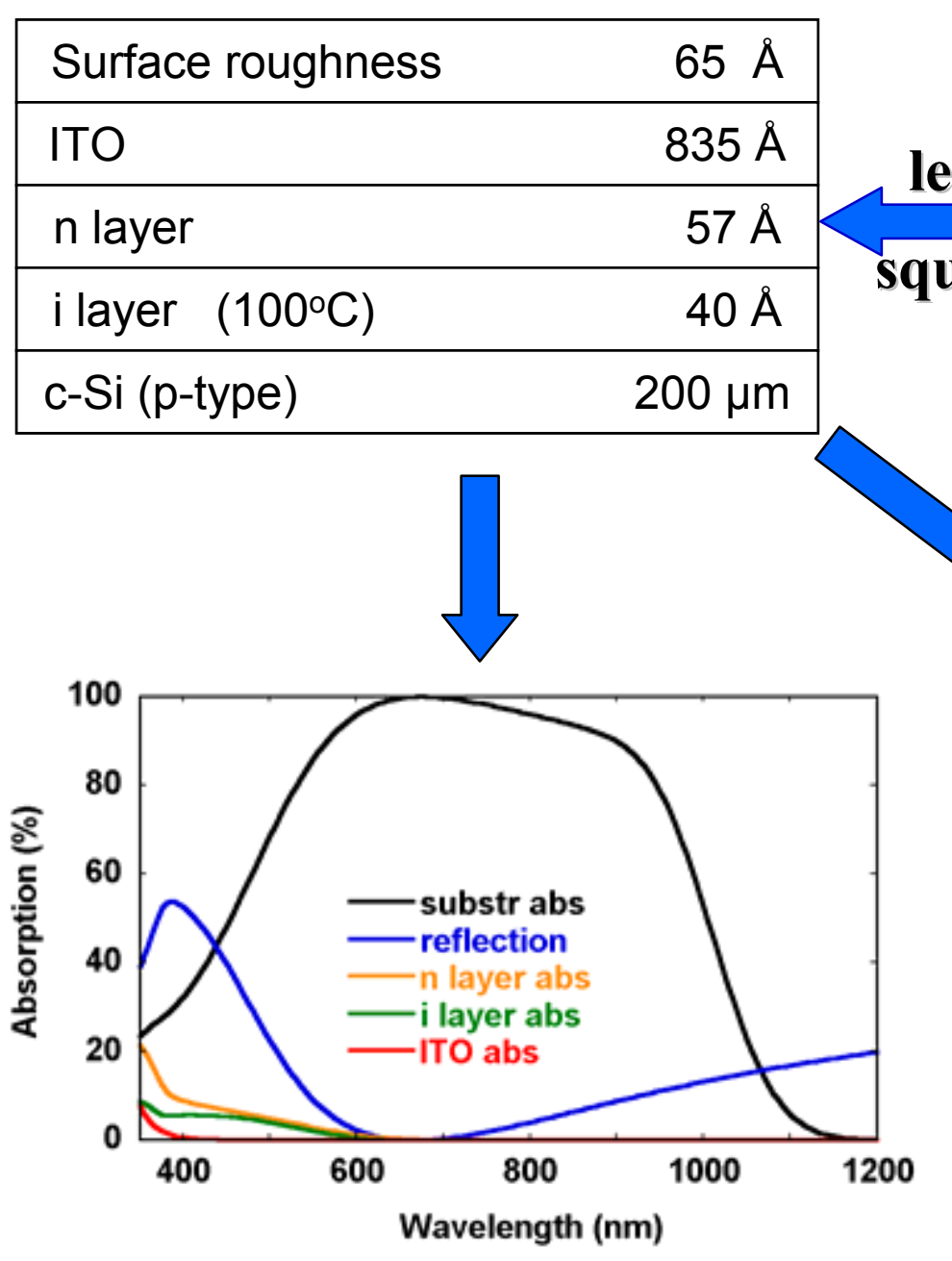

SE measures the amplitude ratio $\Psi$ and the phase change $\Delta$ as a function of wavelength at multiple angles

$\Psi(\lambda), \Delta(\lambda)=\mathbf{f}\left[\mathbf{n}_{\mathrm{i}}(\lambda), \mathbf{k}_{\mathrm{i}}(\lambda), \mathbf{d}_{\mathrm{i}}\right]$ quares

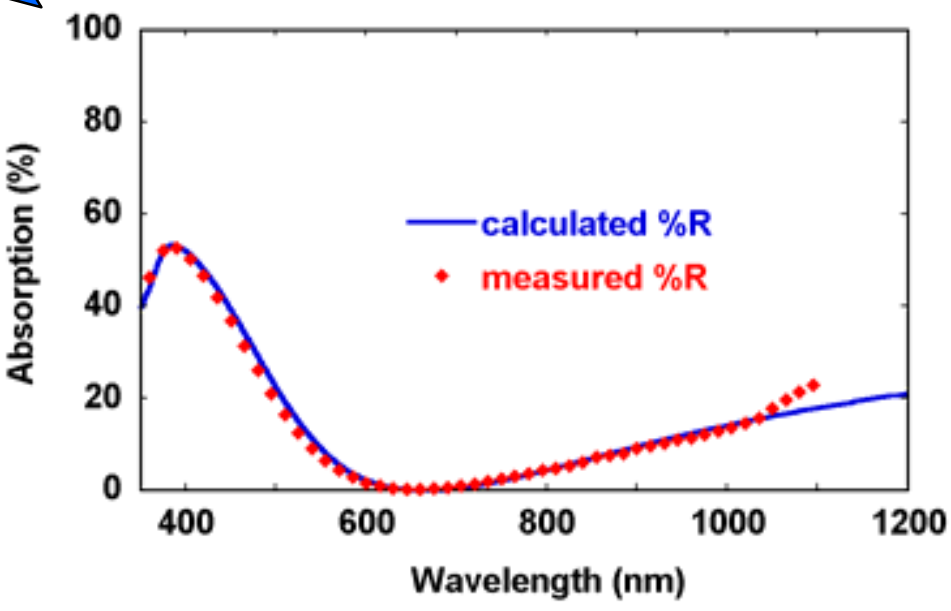




\section{Comparison of SHJ w/diffused junction cell}

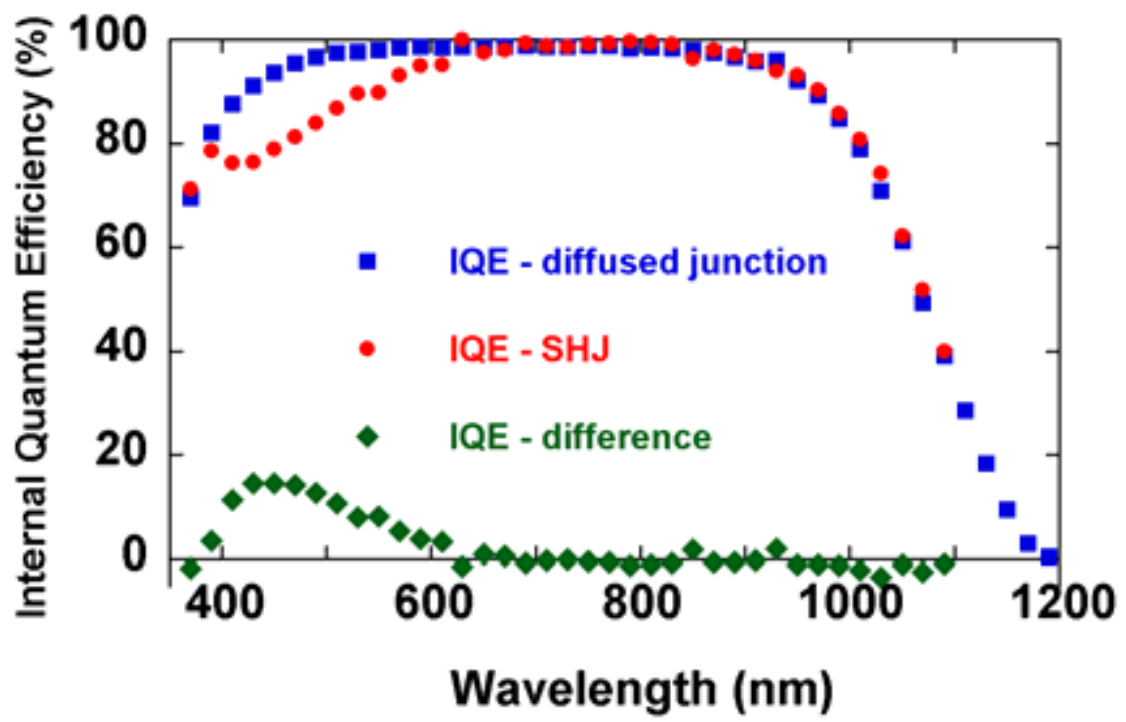

- Two devices are identical except for front junction (both use Al-BSF contact)
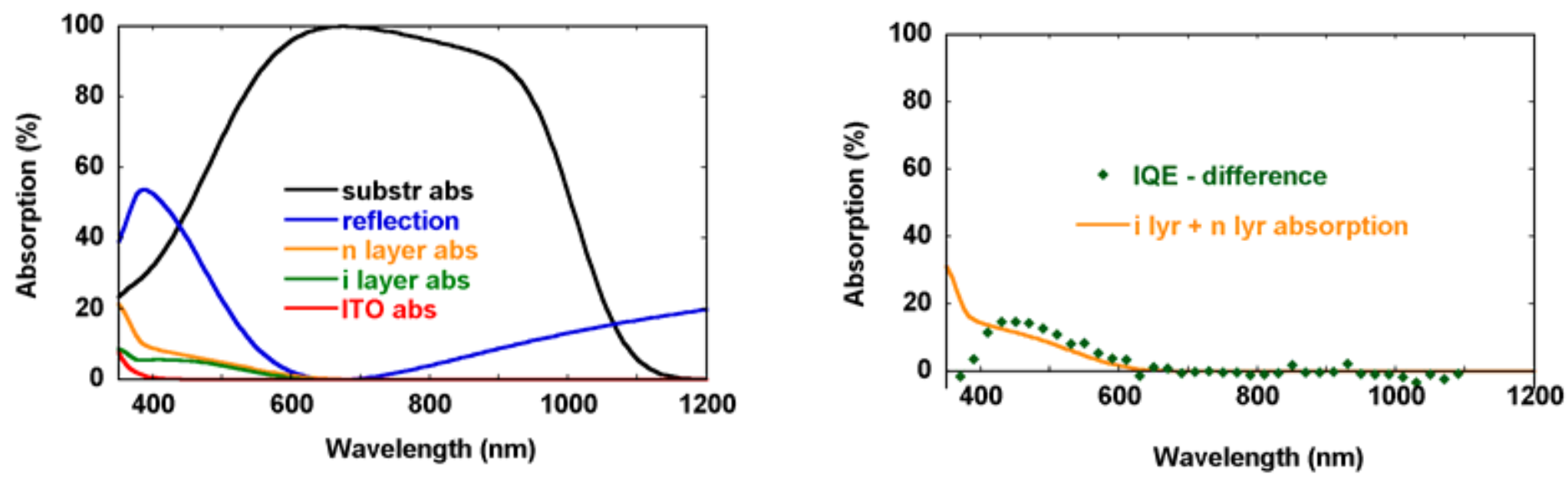


\section{ex situ SE: p-doping comparison}

- 2 nominally identical devices

- $2 \mathrm{sccm}$ vs $18 \mathrm{sccm} \mathrm{B}_{2} \mathrm{H}_{6}$

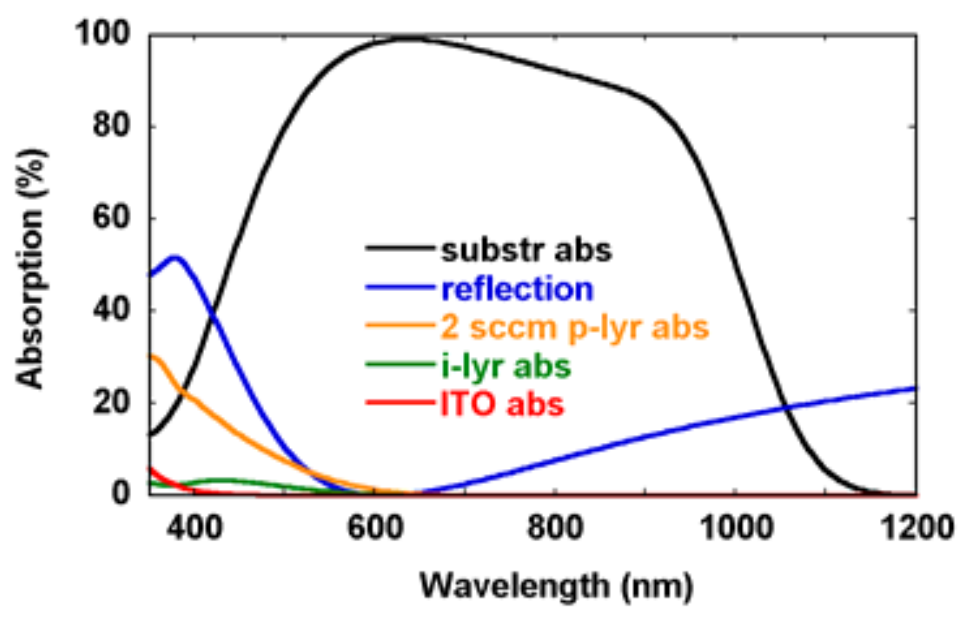

\begin{tabular}{|lr|}
\hline Surface roughness & $56 \AA$ \\
\hline ITO & $752 \AA$ \\
\hline p layer $\left(2 \mathrm{sccm} \mathrm{B}_{2} \mathrm{H}_{6}\right)$ & $118 \AA$ \\
\hline i layer $\left(100^{\circ} \mathrm{C}\right)$ & $35 \AA$ \\
\hline c- $\mathrm{Si}$ & $200 \mu \mathrm{m}$ \\
\hline
\end{tabular}

Dep.

Time

$50 \mathrm{sec}$

$9 \mathrm{sec}$

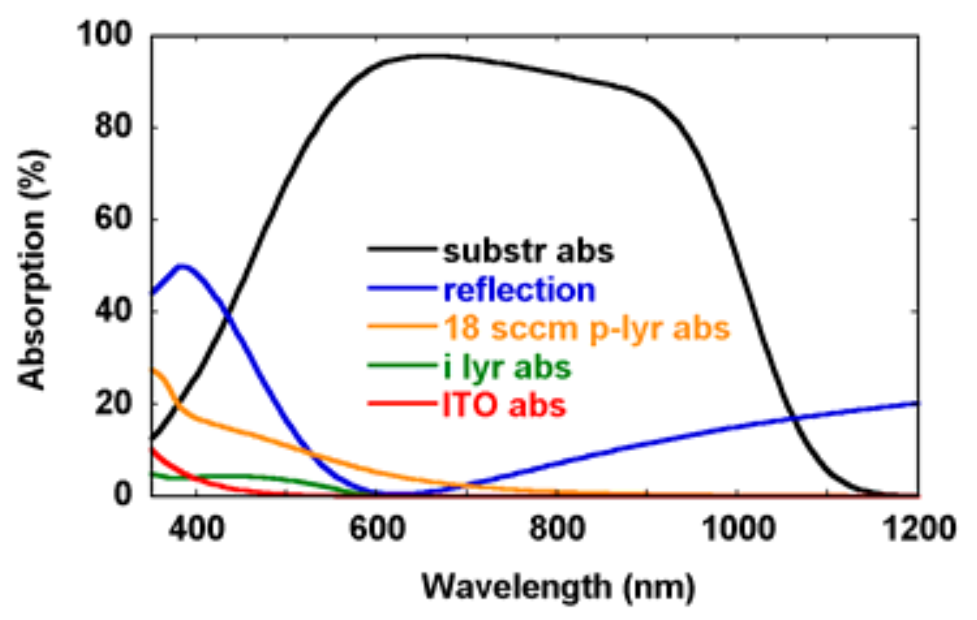

Dep.

Time

\begin{tabular}{|lr|}
\hline Surface roughness & $142 \AA$ \\
\hline ITO & $766 \AA$ \\
\hline p layer $\left(18 \mathrm{sccm} \mathrm{B}_{2} \mathrm{H}_{6}\right)$ & $96 \AA$ \\
\hline i layer $\left(100^{\circ} \mathrm{C}\right)$ & $35 \AA$ \\
\hline c-Si & $200 \mu \mathrm{m}$ \\
\hline
\end{tabular}

$50 \mathrm{sec}$

$9 \mathrm{sec}$ 


\section{Device optical performance comparison}

- Layer thicknesses and optical constants determined by ex situ SE

- Primary difference is $p$ layer doping - flow rate of $\mathrm{B}_{2} \mathrm{H}_{6}$

- Optical model enables calculation of contribution of each layer
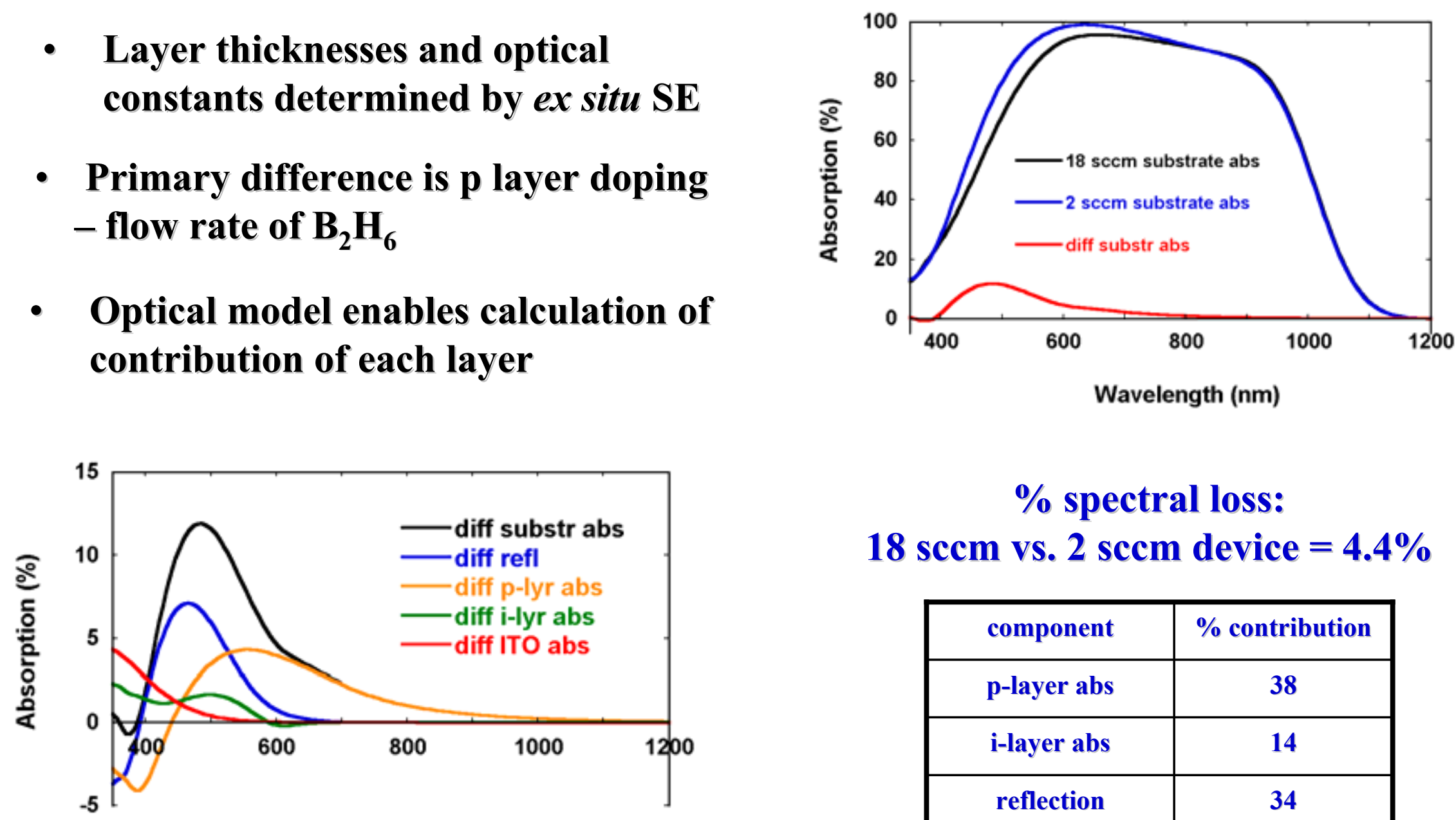

$\%$ spectral loss:

$18 \mathrm{sccm}$ vs. $2 \mathrm{sccm}$ device $=4.4 \%$

Wavelength $(\mathrm{nm})$

\begin{tabular}{|c|c|}
\hline component & \% contribution \\
\hline p-layer abs & 38 \\
\hline i-layer abs & 14 \\
\hline reflection & 34 \\
\hline ITO abs & 14 \\
\hline
\end{tabular}




\section{Summary}

- in situ SE gives insight into growth mechanisms and accurate layer thickness

- ex situ SE measures completed device structures to determine integrated optical properties

- The combination of in situ and ex situ SE provides a powerful method for pinpointing the effects of processing changes in actual SHJ devices and guiding optimization. 


\section{Acknowledgements}

- This work is funded under DOE Contract No. DE-AC3699G010337.

- Thanks to Russel Bauer, Lorenzo Roybal, Helio Moutinho, Bobby To, Yanfa Yan, and Qi Wang of NREL, and to Ajeet Rohatgi and Vijay Yelundur of Georgia Tech. 